\title{
ERRATUM
}

\section{The Use of Handheld Ultrasound Devices - An EFSUMB Position Paper}

Michael Bachmann Nielsen, Vito Cantisani, Paul S. Sidhu, Radu Badea, Tomasz Batko, Jonathan Carlsen, Michel Claudon, Caroline Ewertsen, Carmen Garre, Jordan Genov, Odd Helge Gilja, Roald Havre, Mateusz Kosiak, Wojciek Kosiak, James Pilcher, Helmut Prosch, Maija Radzina, Vasileios Rafailidis, Alexander Rykkje, Andreas Serra, Alexandros Sotiriadis, Mia Østergaard, Christoph F. Dietrich. Ultraschall in Med 2019; DOI 10.1055/a-0783-2303

In the above article, the name of the co-author was misspelled. Right: Alexandros Sotiriadis. 